Portland State University

PDXScholar

1978

\title{
Long-term effects of rape : a literature review and exploratory questionnaire
}

Kathleen June Elsner

Portland State University

Follow this and additional works at: https://pdxscholar.library.pdx.edu/open_access_etds

Part of the Domestic and Intimate Partner Violence Commons

Let us know how access to this document benefits you.

\section{Recommended Citation}

Elsner, Kathleen June, "Long-term effects of rape : a literature review and exploratory questionnaire" (1978). Dissertations and Theses. Paper 2780.

https://doi.org/10.15760/etd.2776

This Thesis is brought to you for free and open access. It has been accepted for inclusion in Dissertations and Theses by an authorized administrator of PDXScholar. Please contact us if we can make this document more accessible: pdxscholar@pdx.edu. 
LONG-TERM EFFECTS OF RAPE: A LITERATURE

\section{REVIEW AND EXPLORATORY QUESTIONNAIRE}

\section{by}

KATHLEEN JUNE ELSNER

A practicum submitted in partial fulfillment of the requirements for the degree of

MASTER OF SOCIAL WORK

Portland State University

1978 
TO THE OFFICE OF GRADUATE STUDIES AND RESEARCH:

The Advisor approves the practicum of Kathleen June Elsner presented June 7, 1978.

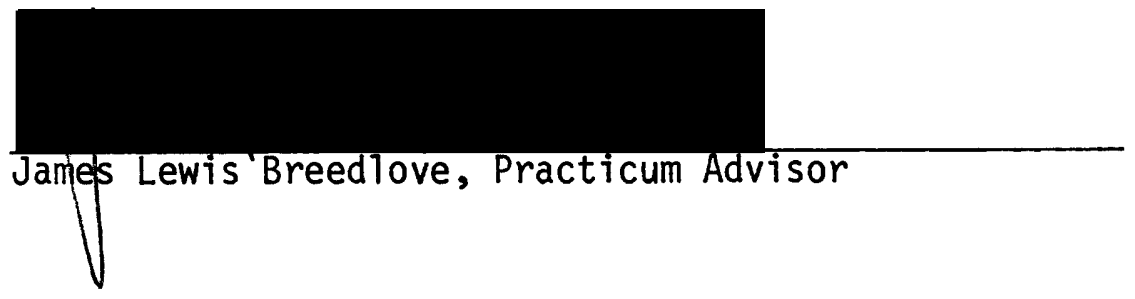




\section{ACKNOWLEDGEMENTS}

I would like to thank my advisor, Dr. James Breedlove, for his overseeing of the practicum, Nancy Koroloff for her help in designing the questionnaire, and Janet Lahti for the encouragement and recommendations she gave without hesitation.

Several others, Lani McDonald and Rick O'Bill, deserve recognition for their willingness to proofread, give support, and share long hours to complete this endeavor. I also extend a "thank you" to the women I have talked with who shared their experiences with me and gave recommendations for the questionnaire. 
TABLE OF CONTENTS

PAGE

ACKNOWLEDGEMENTS .................. $i_{i j}$

LIST OF TABLES ..................... . . . $v$

CHAPTER

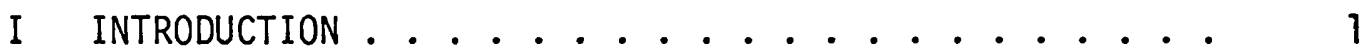

II REVIEW OF THE LITERATURE . . . . . . . . . . . 6

Response Patterns to the Rape Crisis ..... . 7

Reactions to Stress

Three-Phase Response Pattern to Rape

"Rape Trauma Syndrome"

Discussion of the "Rape Trauma Syndrome"

Age-Specific Responses

Discussion of Response Patterns

Issues Relating to Resolution of Rape .....

Victim Sense of Responsibility

Reactions of Others

Issues Related to Developmental Stages

The Victim's View of Herself

Conclusion ................ . .

III PROCEDURE ......................... 41

IV DISCUSSION OF THE QUESTIONNAIRE ......... 45

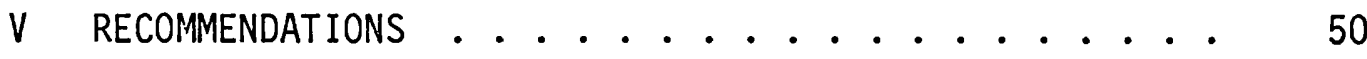

REFERENCES CITED ................ 55

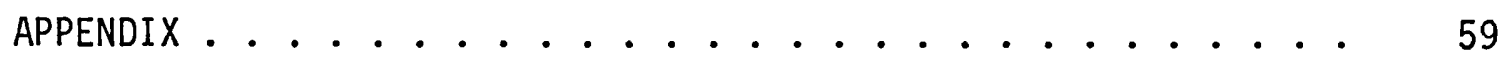




\section{LIST OF TABLES}

TABLE

PAGE

I Distribution of Marital Status by Age $(n=92) \ldots 18$

II Severity of Symptons During Reorganization Process

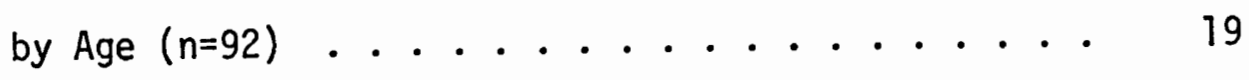

III Percentage Tabulation of Table II for Comparative

Purposes................... 20 


\section{CHAPTER I}

\section{INTRODUCTION}

Much has been reported about the subject of rape through popular literature in the last decade, with particular focus on the treatment of rape victims. Prior attention concentrated predominantly on the crime of rape or the rapist. (Amir, 1971; McDonald, 1971). With the women's movement, emphasis has turned to the rape victim, her reactions to the experience, and the sequelae of the attack. Writers of the women's movement have championed the fight for improved care of female victims and pointed out inconsistent application of justice for rape victims versus victims of other violent crimes (Csida and Csida, 1974; Medea and Thompson, 1974; Brownmiller, 1975; Griffin, 1977). Sociologists interested in victimology have likewise delved into reactions of the rape experience (McDonald, 1971; Schultz, 1973).

Research studies defining the reaction to rape are few. Those that exist focus on victim reactions to the experience, verify the existence of a crisis reaction to the crime, delineate response patterns of the crisis, and attempt to single out sequelae of the event. The studies of Sutherland and Scherl in 1970 and of Burgess and Holmstrom (1973, 1974a, 1974b) have made major contributions in understanding the crisis reactions of victims.

Some studies suggest concerns or issues that result from the rape attack (McCombie, 1976; Notman and Nade1son, 1976; Sprung, 1977). 
Consequences of the rape crisis seem manifest in various areas of the victim's life (Sprung, 1977). One area is victim responsibility for the attack, of which many statements, but few studies, have been made. Other issues cited involve the victim's view of herself after the experience and her relationship with the perpetrator, as well as the response of others to her after the assault (Amir, 1971; Sutherland and Scher1, 1970). There is a paucity of research exploring such issues. Another area often discussed, but not researched, is the "longterm" effects of a rape experience. Some literature alludes to minimal 1ong-term effects (McDonald, 1971; Schultz, 1973; Geis, 1977), while others mention possible or inevitable traumatic reactions (Burgess and Holmstrom, 1974a; Hilberman, 1976; Notman and Nadelson, 1976; Hursch, 1977). Of the few long-range explorations focusing past the initial crisis experience, psychiatrists are often the reporters. Though psychiatrists are not looking specifically for rape sequelae, they often discover in their practice that rape is a major contributing or precipitating event for emotional disorders (Katan, 1973; Peters, 1976; Hilber$\operatorname{man}, 1976)$.

The discrepancies in research findings about long-term effects of rape substantiate the lack of data and knowledge and indicate the need for more study. "There is no documentation of what differentiates rape trauma from other life crises nor is there exploration of the long-term effects of rape on later psychosocial or sexual adjustment" (McCombie, 1976, p. 137). "Little information is available about the long-term consequences of rape because our awareness that rape is a crisis is of recent origin" (Hilberman, 1976, p. 47). Do certain characteristics of 
the attack--the victim-offender relationship, location of the attack, and degree of violence inflicted--affect the subsequent adjustment of the victim? What is meant by "long-term"--six months, one year, three years, a lifetime? The definition in the literature is unclear; in fact, it has, not been addressed.

The purpose of this practicum is to give impetus to the exploration and delineation of long-range effects of a rape experience. This will be accomplished in the following manner: (1) a literature review to (a) review what reactions are known; (b) discuss which response patterns to the crisis may exist; and (c) which issues rape victims express as being difficult or of concern in their adjustment. The literature review will be in Chapter II. (2) Designing a research instrument or questionnaire that can be administered to victims at least one year after the rape. The purpose of the questionnaire is to identify sequelae of the rape still giving the woman difficulties, the degree of difficulty, and to determine if specific reactions take longer to integrate into one's total life experiences. The instrument is presented in Appendix A. It is expected that further critical study and research can be facilitated by its use. Following the literature review, Chapter III presents a short summary and discussion of the procedure. Chapter IV consists of a discussion of the questionnaire and its content, and Chapter V, recommendations.

In this study, the following definitions are used. Rape is considered in the context of the male as the perpetrator of the crime toward a female victim. The act will be defined in terms of penetration of the penis into the vagina, or anus, of the victim against her wishes 
(Brownmiller, 1975), either through force, by intimidation, by betrayal of trust, or by situations that "got out of hand" (Burgess and Holmstrom, 1974b). Included in this definition will be incestuous acts that involve these same sexual acts. Rape of men by women, or other men, or forced sexual contact of women by women is not being considered here.

Defining adjustment to a rape assault is a difficult task. This is due in part to lack of knowledge of how rape affects women, the many variables that may influence adjustment, and a paucity of systematic approaches to data collection.

Webster (1977) defines adjusted as "having achieved a harmonious relationship with the environment or with other individuals," and adjustment as "the act or process of adjusting," or "a means (as a mechanism) by which things are adjusted one to another" (p. 15). In terms of rape, we are looking for the processes by which a woman achieves a harmonious relationship with the reality that she was assaulted. Simply stated the questions become: has she adjusted and by what means did she achieve it?

One follow-up study (Sprung, 1977, Thesis abstract) of victims six to eighteen months after the rape experience notes that:

For some the trauma was "encapsulated" into one area of functioning, which then was avoided. For others the trauma caused a general decrease in the woman's mobility. Almost all of the women became more introspective ( $p .22)$.

Sprung notes also that some developed new adaptive capacities.

Burgess and Holmstrom (1974a) delineate responses of forcible rape victims from their research on a continuum starting. with no symptoms being reported, mild symptoms consisting of minor discomfort, to moderate and severe symptoms, in which the woman has an ability to 
function but with difficulties, phobias, and nightmares. They also report "compounded" reactions in which rape reactivates previously existing difficulties, like drinking and drug usage (p. 983).

Hilberman (1976) discusses a successful response to a traumatic event as evidenced by an ability to talk about the crisis with "affective sharing" and "spontaneous recovery" (p. 34). Comparison of these two abilities with a rape response may or may not indicate a successful adjustment. Perhaps rape, because of its all-encompassing nature, is a trauma in whicin "spontaneous recovery," when speaking about it, is less likely to occur than with other traumas and crises. McCombie notes that "little is known about . . . what represents a 'normal' versus 'pathological' reaction to the trauma of rape" (1976, pp. 137-38). Without such knowledge it is difficult to formulate a definition. The objectives of this practicum are to provide a means for answering such questions as "Has she adjusted?" and "By what means did she achieve it?" It is expected that those women not adjusting can then be discovered earlier and given the support necessary to facilitate the process. 


\section{REVIEW OF THE LITERATURE}

Rape represents an act of violence and humiliation in which the victim experiences not only overwhelming fear for her very existence, but an equally overwhelming sense of powerlessness and helplessness which few other events in one's life can parallel (Hilberman, 1976, p. ix).

While both, assault and rape, are basically acts of aggression and hostility, sexual assault or rape is a total attack against the whole person, affecting the victim's physical, psychological and social identity. Hardly any other crime can be committed against a women with a comparable traumatic impact (Weis and Borges, 1973, p. 72).

The above statements refer to the al1-encompassing trauma inflicted upon a woman by the rape attack. To determine the impact and outcome of such an experience, a review of the studies exploring rape and reactions to rape is warranted. The studies will be reviewed in terms of the victim response patterns, and the areas of adjustment that are mentioned as issues of concern for the woman. The discourse will be divided into two sections. The first section will focus on the reaction patterns of the rape trauma. The second section will discuss the issues of concern as mentioned in the literature and delineated in studies. These issues are incorporated in a questionnaire (see Appen$\operatorname{dix} A)$. 
RESPONSE PATTERNS TO THE RAPE CRISIS

\section{Reactions to Stress}

Before looking at the rape crisis, a look at how people in general respond to stress is indicated. Hilberman (1976) seems to suggest the existence of a parallel in response patterns of the rape trauma and other traumatic experiences. Documentation, however, of how reactions to a rape experience are similar to, or different from, other life crises is scarce (McCombie, 1976, p. 137). Hilberman (1976), in her discussion of the rape victim, cites work by Weiss and Payson (1967) of reactions to stress and discusses it in terms of four clinical phases. She states that "stress reactions represent attempts to defend or restitute the personality from disorganization" (Hilberman, 1976, p. 33). The four stages consist of the anticipatory or threat phase, the impact point, recoil stage, and the post-traumatic phase. The anticipatory condition involves preparing for and protecting oneself against a threat, while integrating the reality that a threat exists with the need to be invulnerable and in control of one's life. In terms of rape, this phase manifests itself in that many women know that the possibility of rape exists, but tend to assume it won't happen to them.

The impact or second phase lasts the interim of the stressful experience. In the instance of rape, it would be the duration of the actual attack. "If the stress is overwhelming, this state of increased vigilance may be followed by diminished alertness, numbness, dulled sensory, affective and memory functions, and disorganized thought content" (Hilberman, 1976, pp. 33-34). Burgess and Holmstrom (1973) express that the rape victims they observed in an emergency room exhibited states of 
shock and disbelief. Others substantiate these findings (Sutherland and Scherl, 1970).

Once the impact of the stressful experience is over, return of sensory, affective, and memory functions, as well as behavioral responses, signals the recoil stage of stress reactions. The return of these functions is of a limited scope.

There is potential for either increased self-confidence or damage to one's self-esteem, depending on positive or negative perceptions of one's behavior during the stress. During this phase of personality reorganization, support or nonsupport by others becomes a critical issue for subsequent psychological events (Hilberman, 1976, p. 34).

As will be seen in discussing the issues arising from the rape experience (section 2 of the literature review), intervention by police and medical personnel along with the reactions of significant others may contribute to or hinder the woman's ability to return to her prior level of functioning (Schultz, 1971; Burgess and Holmstrom, 1974a).

The final stage, the post-traumatic phase, occurs when the individual's view of self is integrated with maximum functioning. In successful coping recall of the traumatic event can occur with "assimilation and affective sharing" and with minimal effects (Hilberman, 1976, p. 34). Less successful responses may leave permanent damage to selfidentity and perceptions of the world. "Evidence of continuing anxiety and depression, anger, guilt, nightmares, and an impaired functional capacity" (Hilberman, 1976, p. 34) may result. Burgess and Holmstrom (1974a) report such symptoms in many rape victims with severe reactions. Others experience being uncomfortable when discussing the symptoms (p. 983). 
Having reviewed reactions to traumatic events, the reactions evidenced in rape victims will be discussed. The first is a pattern consisting of three phases.

\section{Three-Phase Response Pattern to Rape}

As previously mentioned, research concentrating on victim reactions to the rape experience is a relatively new phenomenon. Sutherland and Scherl (1970) have pioneered the effort by specifically focusing on the victim's reactions and needs following the assault. Their stated purpose was to "identify specific predictable sequence of responses to rape" along with mental health interventions for the victim (p. 504).

The study of Sutherland and Scherl was over a one-year period and consisted of a sample of thirteen white, middle-class women. They found a response pattern consisting of three phases: phase one, which they called an acute reaction, comprised of shock, disbelief, and dismay in the immediate hours and days following the attack; phase two, the outward adjustment period, which found the victim continuing with daily life habits and concerns, while discussing little of the rape incident; and phase three, called the integration and resolution period during which the woman, often because of a sense of depression, desired to discuss the incident once again. These stages might have taken place over the duration of one year, but the study left this unclear.

During the phase one acute reactions, the questions of whether or not to seek medical attention, report to the police, and tell family members are noted by Sutherland and Scherl. They suggested a relationship exists between the victim's feelings of responsibility for the rape and the individual(s) she first discusses it with (pp. 504-505). 
Sutherland and Scherl described the second "adjustment" phase as one consisting of denial and suppression (p. 507), whereas during the third phase, "the resolution of the feelings aroused by the rape usually occurs" (p. 508). The resolution emerged in two themes. The first revolved around the need to discuss and integrate the reality of the experience, the woman's view of her complicity in the attack and a "new view of herself" (p. 508). The second issue constituted resolving feelings toward the perpetrator and her relationship with him. The researchers note that this third phase may be marked by "obsessive memories of the rape" (p. 510).

The authors cautioned against using their data for gross generalizations due to the small sample size, yet suggested several issues that subsequent research has supported. One issue was their observation of a "controlled" response during the acute phase. They cited an example of one woman being in control emotionaliy until seeing one of the assailants and then breaking down in tears and needing support. Burgess and Holmstrom (1973) further delineated characteristics of the "controlled" style of responding to crisis in their study. This will be referred to later in the chapter.

Other issues that Sutherland and Scherl noted were related to the ages (eighteen to twenty-four) of the women in their sample. Issues of separating from one's family and the ability to be independent were concerns expressed by the victims. These concerns of separation and autonomy will be returned to later when discussing other research findings in the second section of the literature review. 
As already noted, the concern over the degree of responsibility in the incident was part of the resolution work their study found the woman dealing with in phase three of the three-phased response pattern. Implied was the notion that a relationship existed between how the issues of phase one were handled and the outcome resolution of phase three. The questions of whom to tell (medical, legal personnel, family) and the reactions of those involved with these concerns have been subject to subsequent study and will be expanded upon in the second section of this chapter.

In spite of the data they present, Sutherland and Scherl failed to be specific in a few areas. One was the duration of the "obsessive thinking" about the rape experience in phase three. Had they found such thoughts lasting a month, three months, or longer? Such information could have been informative in determining what constituted a successful or unsuccessful adjustment. Secondly, nothing was mentioned about the degree of violence of each attack, where it took place, if she had known the assailant, nor if such questions had been asked. Likewise, little was mentioned about the previous coping abilities of each of the women. Other studies have discussed that women or young girls who first experience sex in a violent setting may have more difficulty adjusting (Burgess and Holmstrom, 1974a). Sutherland and Scherl did not include any information about this area. Finally, though their study gave some indicators as to what triggered the beginning of the resolution phase, no comment was made of the length of time necessary for its completion. Had this data been provided, further indices for what constituted the 
resolution and the response pattern of a rape experience might have been defined.

Subsequent findings to Sutherland and Scherl's study were victim responses described by Burgess and Holmstrom. It was difficult to determine from their several publications (1973, 1974a, 1974b, 1976) if the same population was used for each discussion, or where overlaps in the data occurred. Their articles will be briefly mentioned here in terms of the main idea to make future referrals to the studies easier. Individual findings will be returned to when appropriate to the discussion. Each of Burgess and Holmstrom's published results seemed to direct attention to a central idea. The first publication of their project (1973) focused on the rape victim in the emergency ward and the coping styles used immediately following the rape attack. The sample consisted of eighty victims seen in the course of the first year of the project. Other demographic data of the victims were for some reason deleted.

In their next article, Burgess and Holmstrom (1974a) focused on a two-phased response pattern they called a "rape trauma syndrome," which they determined from the reactions of ninety-two aduit victims. The researchers found the syndrome expressed in somatic, behaviora1, and psychological reactions or symptoms. The specifics of this particular publication will be returned to momentarily, as the data presented are particularly pertinent to the objective of understanding possible response patterns to the rape assault, and the subsequent issues the victims face in resolving the rape attack. 
An overview of one of their major tenants--that rape victims experience a crisis--is found in Rape: Victims of Crisis (1974b). This volume compiled much of their research and discussed various aspects of rape, including myths, the victim, the rapist and his style of attacking the victim, and with special attention to three categories they suggested to differentiate rape experiences. The categories were: forcible rape, either completed or attempted; victims who are "accessories" to the crime by their inability to consent; and thirdly, victims of sexually stressful situations, where initial consent was granted, but something went wrong and "got out of hand."

The last addition to their findings (1976) discussed in greater detail the mechanisms and behaviors used by rape victims to cope with the crisis. Various techniques were used by the rape victims to survive during and after the attack. These techniques included verbal, cognitive, and physical tactics to resist the danger. Some women, it was found, used several of these behaviors in combination, while others used none.

With these ideas and articles expanded upon, attention will return now to the response pattern Burgess and Holmstrom called the "Rape Trauma Syndrome."

\section{"Rape Trauma Syndrome"}

The Burgess and Holmstrom (1974a) research began in 1972 at Boston City Hospital. Their goal was to specify immediate and long-term effects of rape. They categorized 146 victims into three possible rape situations: forcible rape $(n=92)$, "accessories," and victims of sexually stressful circumstances. The $n$ 's for the latter two categories 
were not indicated in the study, which was focusing on adult forcible rape.

Analysis of the ninety-two adult forcible rape victims led Burgess and Holmstrom to hypothesize the existence of a "Rape Trauma Syndrome." The adult population of their sample was heterogeneous in terms of ethnicity, social class, education, jobs, and marital status. Ages ranged from seventeen to seventy-three years, with about 80 percent (seventy-three) being below the age of thirty. Other studies verify the higher percentage of rape victims falling in the fifteen- to twentyfour-year-01d age category (Goldberg and Goldberg, 1935; Amir, 1971; McCombie, 1976; Hursch, 1977).

The response pattern, or "Rape Trauma Syndrome," was described as . . the acute phase and long-term reorganization process that occurs as a result of forcible rape or attempted forcible rape. This syndrome of behavioral, somatic, and psychological reactions is an acute stress reaction to a life-threatening situation (p. 982).

Burgess and Holmstrom saw the syndrome having two separate phases. The first they call the acute phase, which included the immediate disorganization of life style and was marked by various somatic complaints and emotional reactions, ranging from calmness to crying and shaking. Fear of death was the most prominent expression, followed by self-blame. They noted two styles of coping with the immediate trauma: an "expressed" style, where feelings were verbally stated or shown by crying, smiling, and shaking; a "controlled" style which hid feelings with calm, composed, or subdued affect (1973, p. 1743). Burgess and Holmstrom indicated that weariness from being assaulted while sleeping, a state of 
shock, as well as the masking of feelings, may have contributed to the controlled response.

The second stage began from two to three weeks after the incident and was distinguished by the woman's attempts to reorganize her life. They found changes in motor activity, nightmares, and phobic symptoms prominent in this period.

They designated these symptoms as the reactions of the reorganization phase of the rape trauma syndrome. In their discussion, further characteristics of the nightmares, phobias, and motor activities were noted. Motor activity changes included changing residences, phone numbers, and visiting relatives. Moving often was due to fear of the assailant returning, or attempts to feel in control. Another symptom of the reorganizing phase was the occurrence of "terrifying nightmares." Two themes existed in the nightmares: continual failure to master a situation and finally overcoming the situation, usually the rape attack, which was often accomplished by murdering, maiming, or fleeing from the assailant. No qualification of "terrifying" (waking up screaming, perspiring, rapid pulse, physically trembling) was mentioned. The last reaction they discussed involved the concept of "traumatophobia," which they borrowed from Sandor Rado's post-war trauma studies (1948). Their data revealed twenty-one women as having experienced symptoms that interfered with their life styles. They found that rape victims experienced phobias of several kinds: fear of being indoors, fear of being outdoors, fear of being in crowds, of being alone, of people being behind them, and sexual fears (especially those who had experienced no previous sexual activity). 
It is interesting to note that the responses of nightmares and phobias parallel those Hilberman (1976) discussed as unsuccessful of stress experiences. Whether or not phobias and nightmares indicate unsuccessful adjustment to a rape experience is not determined. They may be a resolution mechanism: indicators of the woman's coping style and an expression of the degree of trauma she is experiencing. Burgess and Holmstrom seemed to indicate this as their interpretation. It would have been helpful to know if certain characteristics of the attack (the degree of violence, relationship with the offender, the place of the assautt) correlated with the prominence of phobias and nightmares, their duration, and which, if any, figures more predominately. Research to determine the correlation between characteristics of the assault and these reactions of phobias and nightmares is needed.

The Burgess and Holmstrom data also revealed two other responses or reactions to rape. If the women had a past history of, or current struggles with physical, social, and/or psychological difficulties, this "compounded" the effects of the rape (p. 982). Eighteen women (20 percent) of their sample exhibited such reactions.

It was noted that this group developed additional symptoms such as depression, psychotic behavior, and acting-out behavior, psycho-somatic disorders, suicidal behavior, and acting-out behavior associated with alcoholism, drug use, and sexual activity (p. 985).

The other response was one they called the "silent reaction." When interviewing some of the victims, it was found they had experienced a rape earlier in their lives, but had never told anyone about it. The current rape crisis had brought to the surface the earlier assault. The data analysis gave no indication if these women experienced the 
"rape trauma syndrome" differently or were more prone to "compounded" reactions than the other women. Burgess and Holmstrom failed to attend to the issue.

\section{Discussion of the "Rape Trauma Syndrome"}

Overal1, Burgess and Holmstrom figure prominently in the research of rape victim reactions. Their data verify that the rape experience is a crisis for the victim and a violent life-threatening act. The research negates the prevalent notion that rape is a sex crime. (For further information, see Rape: Victims of Crisis, 1974b.) Their data also give credence to the existence of an identifiable response pattern to a rape trauma, the awareness of which allows for more goal-directed interventions.

Another contribution is the symptoms they define in the reorganization stage. Though not stated as a continuum, the symptoms they report could line up in such a manner. On one end of the spectrum are no symptoms being reported, with "compounded" symptoms at the opposite end. In between are mild or minor discomforts where the victim can discuss the symptom and have a sense of control over it. Moderate to severe responses where phobias are present are in the middle of the continuum. The women reporting these symptoms can live their daily lives but feel disturbances in functioning. Burgess and Holmstrom's work begins to define the symptomology of a rape experience and allow for more systematic research to verify, substantiate, and expand upon their findings. Such efforts are sorely needed if the rape victim is, and her reactions are, to be fully understood. 
Several areas of their research suffer from the absence of discussion. It is unclear, for instance, what they mean by "long-term" consequences to the rape experience. Do they consider six months, twelve months, or over a year as long-term? With lack of an explicit definition, one can only speculate about the duration of the pattern they report.

Another deficiency is the discrepancy between the numbers they report in two of their tables, which becomes confusing when reviewing the data. Table I (p. 982) distributes the victims according to marital status and age. Table II (p. 983) describes the reported symptoms of the reorganization phase by age. For comparative purposes, Table II will be presented on page 19, and Table I below.

\section{TABLE I}

DISTRIBUTION OF MARITAL STATUS BY AGE $(N=92)$

\begin{tabular}{lcrcccc}
\hline & \multicolumn{5}{c}{ Age (in Years) } \\
\cline { 2 - 6 } & Marital Status & $17-20$ & $21-29$ & $30-39$ & $40-49$ & $50-73$ \\
\hline Single & 29 & 25 & 0 & 2 & 1 \\
Married & 2 & 1 & 2 & 2 & 0 \\
Divorced, separated, or widowed & 2 & 6 & 7 & 2 & 2 \\
Living with a man by consensual & & & & & 0 \\
agreement & 4 & 5 & 0 & 0 & 0 \\
\hline
\end{tabular}

SOLRCE: Burgess and Holmstrom, 1974a, p. 982.

The numbers for the age categories when totalled do not agree. Table I has ages $17-20$ totalling 37 , ages $21-29$ totalling 37 , and ages 30-39 being 9. Table II charts the age category of 17-20 as having 38 respondents, ages 21-29 totalling 35, and women 30-39 years old total1ing 10. The two categories of older women $(40-49,50-73)$ agree on 


\section{TABLE II}

SEVERITY OF SYMPTOMS DURING REORGANIZATION

PROCESS BY AGE $(N=92)^{a}$

\begin{tabular}{llllll} 
& \multicolumn{5}{c}{ Age (in Years) } \\
\cline { 2 - 5 } Severity of Symptoms & $17-20$ & $21-29$ & $30-39$ & $40-49$ & $50-73$ \\
\hline
\end{tabular}

No symptoms: no symptoms reported and symptoms denied when asked about a specific area

Mild symptoms: minor discomfort with the symptom reported; ability to talk about discomfort and feeling of control over symptom present

16

0

2 1

Moderate to severe symptoms: distressing symptoms such as phobic reactions described; ability to function but disturbance in 7 ife style present

Compounded symptoms: symptoms directly related to the rape plus reactivation of symptoms connected with a previously existing condition such as heavy drinking or drug abuse No data available

$\begin{array}{lllll}7 & 5 & 3 & 3 & 0 \\ 0 & 5 & 4 & 0 & 0\end{array}$

SOURCE: Burgess and Holmstrom, 1974a, p. 983.

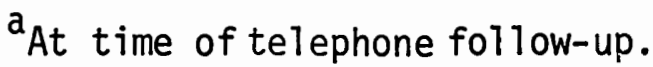

both tabies. The $\mathrm{N}$ for each is 92 . It is possible that birthdays account for the differences, as Table II are follow-up contacts, but this is speculation.

Percentages in each response category would also have been helpful when comparing data. Without percentage tabulation, difficulty occurs when comparing the statement: "The number of victims over age 30 was sma11, but the data at least suggest that they might have been more prone to compounded reactions than the younger age groups" (p. 983), 
with statistics from Table II. Table II reveals twelve victims under thirty years as having the compounded reaction, and six over the age of thirty with the same symptoms. At first glance the data and the statement seem inconclusive. To facilitate comparison, percentages have been computed and are presented in Table III. (Tabulating percentages show 16 percent (12/73) under thirty having compounded symptoms as compared with 31.5 percent $(6 / 19)$ of women over thirty and older. The use of percentages would have added clarification and validation of the statement. As it is, one must speculate on the support of their hypothesis.

TABLE III

PERCENTAGE TABULATION OF TABLE II FOR COMPARATIVE PURPOSES

\begin{tabular}{|c|c|c|c|c|c|c|c|c|c|c|}
\hline \multirow{3}{*}{$\begin{array}{l}\text { Severity of } \\
\text { Symptoms }\end{array}$} & \multicolumn{10}{|c|}{ Age (in Years) } \\
\hline & \multicolumn{2}{|c|}{$17-20$} & \multicolumn{2}{|r|}{$27-29$} & \multicolumn{2}{|c|}{$30-39$} & \multicolumn{2}{|c|}{$40-49$} & \multicolumn{2}{|r|}{$50-73$} \\
\hline & $\mathrm{N}$ & $\%$ & N & $\%$ & $\mathrm{~N}$ & $\%$ & $\mathrm{~N}$ & $\%$ & $\mathrm{~N}$ & $\%$ \\
\hline No symptoms & 7 & 18.5 & 4 & 11.4 & 2 & 20.0 & 0 & 0.0 & 0 & 0.0 \\
\hline Mild & 12 & 37.5 & 16 & 45.7 & 0 & 0.0 & 2 & 33.4 & 1 & 33.4 \\
\hline $\begin{array}{l}\text { Moderate to } \\
\text { Severe }\end{array}$ & 12 & 31.5 & 5 & 14.3 & 1 & 10.0 & 1 & 16.6 & 2 & 66.6 \\
\hline Compounded & 7 & 18.5 & 5 & 14.3 & 3 & 30.0 & 3 & 50.0 & 0 & 0.0 \\
\hline No data & $\underline{0}$ & 0.0 & 5 & 14.3 & 4 & 40.0 & $\underline{0}$ & 0.0 & $\underline{0}$ & 0.0 \\
\hline Totals & 38 & 100.0 & 35 & 100.0 & 10 & 100.0 & 6 & 100.0 & 3 & 100.0 \\
\hline $\begin{array}{l}\% \text { of } N \text { in } \\
\text { each age } \\
\text { group }\end{array}$ & & 41.3 & & 38.0 & & 10.9 & & 6.5 & & 3.3 \\
\hline
\end{tabular}

Age-Specific Responses

Remarks have been made of responses by rape victims being determined to some degree by developmental stages (Peters, 1973, 1976, 1977; Burgess and Holmstrom, 1974a; Notman and Nadelson, 1976). The 
preceeding discussion of the literature review has focused primarily on response patterns found in adult victims of forcible rape. In terms of younger victims, the literature often discusses the effects of rape but rarely touches upon the response patterns of these victims. Following are a few remarks about development and reaction patterns as suggested by the literature. The issues centering around age variables will be discussed in the next section of the literature review.

The major reaction was found to be withdrawal (Peters, 1976). "Minors were rated more withdrawn than adults, which is consistent with observations from private psychiatric practice" (Peters, 1977, p. 352). Mills (1977) suggests this withdrawn response is similar to the adult "controlled" response found by Burgess and Holmstrom (1973) (Mills, 1977, p. 73). No statement is made regarding children or adolescents has having an "expressed" style. Perhaps a withdrawn reaction is the major coping style for the younger victim.

As already noted in the literature review, adult victims of forcible rape display several reaction patterns. Whether or not these patterns apply to the younger victim is not stated. Paucity of studies defining the younger victim's response dictates a need for such research. Furthermore, when the inconsistencies in the literature of the effects of rape on the younger victim (no harm to tremendous difficulties in recovering), and the limited knowledge of how the younger woman responds to the assault are considered, Targe gaps in the knowledge become apparent. A desperate need for study clearly exists. 
Discussion of Response Patterns

It is important to comment on the different response patterns that Burgess and Holmstrom. (1974a) suggested and the three-phase pattern indicated by Sutherland and Scherl (1970), since these two studies are the foremost in the field at this time. Burgess and Holmstrom seemed to have collapsed phases two (pseudo-adjustment) and three (resolution) of Sutherland and Scherl's response pattern into one phase, which they simply called the reorganization stage (McCombie, 1976).

No comment, nor explanation, is offered by Burgess and Holmstrom of what appears to be an oversight of the pseudo-adjustment phase determined by Sutherland and Scherl's research. One can only speculate that Burgess and Holmstrom either saw no such "pseudo-adjustment" phase, or overlooked this depressed state. Sutherland and Scherl cautioned that it was easy to overlook (1970). Possibly this denial aspect to the response pattern is an issue related to age variables, as the Sutherland and Scherl sample consisted of single, nineteen- to twenty-four-year-old women. It has been noted that women in this age category are more controlled in responding to rape than other age categories (Notman and Nadelson, 1976; Peters, 1977, p. 352).

It would be interesting to know if the fifteen- to twenty-fouryear-olds of Burgess and Holmstrom's study showed more signs of denial or control than the other age groups. Should this be so, Sutherland and Scherl's findings of a denial phase might be peculiar to the younger rape victim.

As stated earlier, the Burgess and Holmstrom population, because of its heterogeneity and population size, lends itself to 
generalizations easier than the small sample of Sutherland and Scherl. Thus determining which of the two response patterns delineated by the research has greater validity, and making decisions about which is more accurate, is difficult. Further research is indicated for clarification and validation of what the rape victim response pattern consists of. Attention will now be focused on the various concerns the literature has reported rape victims expressing as part of the reorganization of their lives.

\section{ISSUES RELATING TO RESOLUTION OF RAPE}

Rape is a form of mass terrorism, for the victims of rape are chosen indiscriminately, but the propagandists for male supremacy broadcast that it is women who cause rape by being unchaste or in the wrong place at the wrong time--in essence, by behaving as though they were free (Susan Griffin, 1977, p. 66).

Rape obviously does not merely harm the victim--its impact is felt by the significant others in the victim's life. Indeed, the very fabric of human relationships is disrupted by the rape experience (Pepitone-Rockwe11, 1978, pp. 524-25).

Some interviewees claim that the rape resulted in a decrease in self-esteem, consequential inability to entertain a normal heterosexual relationship, and ultimately suicidal behavior (Weis and Borges, 1973, p. 98).

This section of the literature review will focus on the various issues, as indicated by the research, that exist for the rape victim, and particularly the concerns that may influence her subsequent adjustment. Research data are only now addressing some of these concerns. Many of the issues seem to interrelate with each other, making cause and effect relationships difficult to assess and measure. The procedure will be to single out the prominent issues and discuss the research 
substantiating each area. Those issues needing further study will be indicated as well.

Victim Sense of Responsibility

Blaming the Victim. The rape victim's sense of her responsibility for the assault, her feelings toward the assailant, and the degree of relationship she has had with him have been cited as issues related to resolving the rape trauma. Initial research of rape attended to the crime, the offender and his prosecution, which in many instances queried the victim as to her role in the assault. Amir (1971) applied the phrase "victim precipitated" to some instances of rape in his study. The outcome of this focus, plus the laws requiring "proof" of the rape, have placed blame on the victim for responsibility in the act. The legal aspect of rape has required that evidence of a struggle be exhibited by the victim to prove, in essence, she did not really "want it," nor that she was simply "getting back at a man" by claiming he raped her. The implication of this line of thinking is clear: if she cannot produce hard evidence, she really did "want it."

Research discredits this assumption or bias. Statistics reveal that even when attempting to escape, the rape is often completed. Goldberg and Goldberg (1935) stated that more than half of their large sample $(1,400)$. were victims in spite of their attempts to escape the attack (p. 300).

The victim's concern and need to deal with feelings of responsibility seem to be in part the result of society's attitude. of "blaming the victim" (Burgess and Holmstrom, 1974a). McCombie (1976) found 18 percent of her population "explicitly stated that they were troubled 
about their role and responsibility for what had happened" (p. 153). The woman, who has difficulty or is unable to free herself of the attitude of society, and sees herself at fault or an "accomplice" for the rape, can be expected to experience more difficulty in adjusting than the woman who does not experience this concern. Research has indicated the woman's lack of struggle is a function of dynamics other than the commonly held notion that she wants to be raped, or was "asking for it."

Methods of Resisting. Amir (1971) found that "when confronted with a threat to her life or physical well-being, the victim was not willing to resist or fight" ( $p$. 169). Other studies have substantiated this finding and offered further explanations (fear, shock, age) for the woman's "apparent" unwillingness to resist (Goldberg and Goldberg, 1935; Weis and Borges, 1973; Burgess and Holmstrom, 1974a, 1976; Notman and Nadelson, 1976). Research on responses to crisis has indicated that when people are confronted with overwhelming crises, there is a period of time in which no activity takes place. In such instances, people seem to be frozen with fear and shock, and this has been found to occur in some instances with the rape victim.

Many women, when faced with a sexual attack and realizing their psychological and physical inability to protect themselves, are immobilized with fear. Generally characteristic of a crisis is a delayed reaction before the individual perceives and defines the situation. Initially the victim tends to deny the reality of what is happening. The stronger the inclination for denial, the longer will be the period of inaction (Weis and Borges, 1973, p. 83).

Burgess and Holmstrom (1976) delineated the rape crisis into three aspects and looked at the coping mechanisms the victims. used to prepare for the attack, defend themselves when it was imminent, and then how to flee the situation. They found the adult women of their study to use 
verbal, cognitive, and physical tactics to ward off the attack. Some of the victims displayed several strategies, or utilized none. Weis and Borges (1973) further stated that "the most effective ego defense against traumatizing experiences is denial of personal involvement" (p. 99). Detachment and apparent lack of struggle may represent coping behavior on the part of the victim and also represent a way of resisting. Thus, it seems there are a variety of responses to the rape attack. Inactivity as a response, which has been interpreted by some to mean "wanting to be raped," seems a function of fear, shock, disbelief, and indecision when overwhelmed, as well as a cognitive choice to comply in order to remain alive.

Amir (1971) divided degrees of resistance into three categories. He found women over thirty resist more, women between fifteen and thirty using fighting tactics more frequently, and younger victims more submissive when threatened. Why this was so is unclear. One can speculate that age and perception of the degree of threat were involved. The degree of resistance and self-recrimination after the attack may be more pronounced for individuals who are more submissive, but research has neither substantiated nor refuted this. In spite of the findings of Burgess and Holmstrom (1976), more knowledge about the correlation between coping strategies and subsequent feelings and adjustment is needed.

Victim/Offender Relationship. One study indicated that as the rape victim dealt with accepting the reality of the attack, one of the questions she asked herself was how she got into the situation in the first place (Burgess and Holmstrom, 1974a). Part of this debate 
depended on how she viewed her relationship with the assailant, and the locality where the rape occurred. Various facets concerning the victim/ offender relationship have been. researched. Sutherland and Scherl (1970) found that one element of integrating the rape experience in one's life was resolving the issue of degree of relationship, and any consequent responsibility the woman might feel because of her perception of the relationship.

In determining any responsibility, it seems the rape victim might examine a variety of aspects concerning the assault. One aspect is the way the attack occurred, which seems to be determined by the degree of relationship existing between the offender and victim.

Demographic data place the highest incidence of rape (43 percent) occurring with strangers; neighbors and acquaintances are next in frequency (Amir, 1971; McCombie, 1976). Hursch (1977) found 50 percent of rapes of children in her sample were committed by strangers, contrary to common belief that most children are attacked by neighbors or friends.

One study found the reverse true: a higher incidence (43.8 percent) of rape occurred with friends and acquaintances, and strangers next (26.3 percent) (Goldberg and Goldberg, 1935). Their finding was possibly due in part to the age of the population studied, which was mostly teenagers. Generalizations to the whole population would not be appropriate.

Because the data exist only on reported incidences, it is possible that the other categories, besides stranger rapes, could be more frequent. Given the prevalent thinking that a woman's responsibility for 
the rape increases with familiarity of the perpetrator, it is likely the closer the relationship the less reporting would occur.

Burgess and Holmstrom (1974b) divided rape assaults into two styles: the "blitz" or sudden and arbitrary attack, and the "confidence" style, reminiscent of the con game. The confidence rape is described as having several aspects to it. The rapist can "capture the victim" by initiating a relationship in order to interact and later rape the woman; or use a prior relationship, as in the instances of neighbors, friends, acquaintances, and betray the trust to make the assault. "The assailant uses his relationship with the victim to justify his being in the situation. He then deceives the person by not honoring the bounds of the relationship" (Burgess and Holmstrom, 1974b, p. 8). It would seem that the woman who experiences the "confidence" rape could have more difficulty sorting out her feel ings of responsibility and perhaps have more trouble resolving the incident. Peters (1976) suggested this is true of child victims (p. 417).

The degree of the relationship is an issue yet to be fully understood. McCombie (1976) sums up the current status of this issue by stating: "Whether or not the victim knew her assailant is frequently referred to as an important variable but its significance remains unclear" (p. 141):

Several other aspects of the attack may relate to how the woman perceives her involvement and sense of responsibility, the degree of violence by the offender, the presence of alcohol by the rapist and victim, and the location where the crime occurred. These three aspects 
may determine if the woman perceives the attack as forcible rape without her participation.

Degree of Violence. Amir's study (1971) found violence and force more pronounced in rapes by strangers. This violence included physical beating, strangulation, and threats with a weapon, and left little doubt that forcible rape had occurred. Burgess and Holmstrom (1973) reported that almost one-half of their sample were threatened with a weapon. Others reported they were held at the throat with death threatened for noncompliance. In the cases of child rape, Peters (1976) found bodily harm threatened in 31 percent of the cases.

The analysis of the type of situation is complicated when a relationship between the offender and the victim existed. The relationship could serve as the means of getting the two individuals in physical proximity as in the "confidence" style of rape previously mentioned. In this case, less force would need to be applied to establish the situation, while the element of surprise would still exist. Speaking of the woman, Weis and Borges (1973) noted that the "reaction time will be especially prolonged if she knows the offender and trusts him not to harm her" (p. 83). The woman's feelings of guilt may be particularly heightened by this type of attack, as she may not realize that she had been conned, plus, the lack of physicial evidence of struggle together with the established relationship may cause greater feelings of responsibility for the rape.

Alcohol and Rape. It also seems likely that if the woman knows the individual, his presence in her living situation, or the consumption of alcohol in her presence, or with her, could be considered normal 
behavior. In Amir's sample (1971) alcohol was involved with the rape 34 percent of the time. He also found a significant association between alcohol and sexual humiliation, and the use of violence. Another interesting correlation Amir. found was that alcohol in one or both of the parties was significant in planning the "set-up" of the victim. Thus what might appear to be friends, or acquaintances, enjoying a drink together, may in fact be a set-up for a rape. The "con" involved may have some significance in terms of adding confusion and complicating the issues the woman would need to deal with in order to resolve the rape in her own mind.

Location of the Rape Assault. When rape occurs in the home of the victim, another twist is added. One usually views. "home" as a relatively safe place, both psychologically and physically. To be assaulted in such a setting calls into question one's overall vulnerability in life and the ability to be autonomous and in control. Whether or not women attacked under such circumstances have more difficulty in adjusting to the experience than women suddenly surprised remains to be verified. Such data could serve to determine which issues may be more troublesome in her subsequent resolution and adjustment to the experience.

Feelings of Guilt. Guilt has also been discussed as significant in the rape experience. It has been stated, though not thoroughly supported, that the degree of guilt and ambivalence experienced determined the time that elapsed between the attack and reporting it to the police (Notman and Nadelson, 1976; McCombie, 1976). "The guilt of the victim is further. increased by focusing on the sexual rather than the violent aspect of the experience" (Notman and Nadelson, 1976, p. 410). A 
question arises out of this statement that could be answered by research: the less the violence, or if a "confidence" attack, the more the focus would center on the sexual aspect of the crime and increase the feelings of guilt.

Hitberman (1976) suggested that a woman may incorporate guilt and self-blame as a defense mechanism to lessen her fear about having lost control over her own life. The implication suggested is that the more a woman needs to feel that she is in control, the more she will experience guilt for her inability to control circumstances. In this manner the assault becomes less frightening and the trauma more manageable. The correlation between guilt and/or shame to feelings of responsibility for the assault is unclear and in need of verification.

\section{Reactions of Others}

One of the major concerns the rape victim faces is the reactions of those around her. Studies have indicated that the treatment received by police, medical personnel, and family members are of paramount importance to the woman subjected to the rape experience (Sutherland and Scher1, 1970; Burgess and Holmstrom, 1973, 1974a; McCombie, 1976; Frances-Pepitone, 1978). The recent surge of special services in emergency wards and police precincts and the training for the personnel involved with the rape victim, testifies to the further trauma inflicted

- upon the rape victim by medical and legal authorities (Hardgrove, 1976; Stratton, 1976; Russel and Beigel, 1976; Mills, 1977). Burgess and Holmstrom (1973) found many women grateful for the help the police gave but "talking with them is one more stressful situation" (p. 1741). 
The reactions of family members and other significant persons has been noted in the Titerature (Sutherland and Scher1, 1970; Burgess and Holmstrom, 1974a; Hilberman, 1976; McCombie, 1976; Pepitone-Rockwe11, 1978). McCombie's data revealed that 14 percent of her sample were concerned about how others would respond (1976, p. 154). Several others, when discussing younger victim reactions, suggested that the parental handling of the matter greatly influenced the child's reaction and adjustment (Schultz, 1973; Peters, 1973, 1976). Mills (1976) stated that the parents have a tremendous effect on the child victim's subsequent adjustment.

The parents are the most important people affecting how the child copes with the sexual assault. If they deny anything serious has occurred and ask the child to remain quiet out of their own embarrassment or shame, the child's ambivalence can be intensified and the child will be deprived of the necessary support needed to fully discuss and then adjust to the rape (Mil1s, 1976, p. 74).

The degree of subsequent trauma and adjustment difficulties for the child are issues on which various discussions in the literature have presented conflicting data (McDonald, 1971; Schultz, 1973; Hilberman, 1976; Hursch, 1977).

In terms of the adult rape victim, Sutherland and Scherl noted, "In most instances, a marked decrease in the patient's anxiety and other symptoms occurred after. she had been able to discuss the incident with her family" (1970, p. 505). When considering the nature of the traumatic event and a woman's sense of helplessness, the support of others has been found to be important. Hilberman's discussion (1976) of the recoil phase in traumatic events mentioned the dependency needs of the 
individual and support of others as crucial to adjustment and selfconcept reintegration.

Often it has been reported that the family members themselves are shocked, and have difficulty in supporting the victim. One study noted:

The victim's family and others may believe that "she asked for it" since they believe that rape can only occur that way.

Rather than support the victim emotionally, the family may withdraw, be openty critical, or wonder how they failed as a family (Pepitone-Rockwe11, 1978, p. 523).

The rape experience becomes an event with which each family member must contend. Suddenly they have been thrown into looking at themselves, their own reactions to the trauma, and their own vulnerabilities. It has been found that the trauma necessitated, then, educating the family about the violent nature of rape, clarifying misconceptions about rape, plus supporting them as they dealt with their individual reactions and feelings (Mills, 1977). In all, the assault serves to significantly affect those in the victim's social network, as well as her life.

\section{Issues Related to Developmental Stages}

Mention has previously been made of the different response patterns of adult rape victims. More definitive research of age variables has revealed certain issues as more critical to different developmental stages and life situations (Peters, 1976; Notman and Nadelson, 1976; Mi11s, 1977).

Notman and Nadelson divided their population into three groupings, the younger victims (seventeen to twenty-four years), the divorced or separated woman, and the woman in her middle years. They found the younger victims having issues of separation and independence/dependence renewed by the rape trauma. The woman's concerns of autonomy and 
ability to care for her own needs were called into question. They discovered, too, that future sexual relationships were impacted by the rape. "This is especially true for the very young woman who may have had her first sexual experience in the context of violence and degradation" (p. 411). Often gynecological examination became a troublesome experience for these young victims.

The middle-aged woman had certain areas that rape unsettled as we11. Notman and Nadelson found a woman in this age span "is often in a period of critical reassessment of her life role, particularly in the face of changed relationships to her grown-up children" (1976, pp. 41112). She was noted as passing through a time in which many changes were occurring in her life and was perhaps feeling more insecure in her ability to control the changes. She may also have been concerned about her sexual inadequacies and changes. "For the middle-aged married woman, issues of her ability to have control and her concerns about independence are particularly important" (Notman and Nadelson, 1976, p. 411). Burgess and Holmstrom's conclusion (1974a) that the older women had more difficulties adjusting to rape was substantiated in part by the research of Notman and Nadelson. Further study to clarify and support these ideas is needed.

The divorced or separated woman in Notman and Nadelson's population seemed to receive more criticism and was more suspect than the other women they discussed: "Her lifestyle, morality, and character are frequently questioned" (p. 411). It seems that reactions of others are more harsh on the woman finding herself in these. life circumstances. As with the other women of their sample, the concern of being able to 
function independently was disputed. The underlying assumption being implied seemed to be that the divorced woman was somehow morally corrupt, or more prone to being so, apparently because of her status as a divorced person. A related issue was that of her responsibility for the rape: because she is single, she must have "wanted it."

The child victim has been the target of much speculation in terms of long-term effects and adjustment. Peters (1973) differentiated responses by children under and over age six. He found the child under six more prone to blame the self and incorporate the parental guilt reactions as his or her own. It would seem the child under six, then, would experience a great deal of guilt and subsequent lowered selfesteem. Peters suggested that those victims over six years of age focused their guilt on sexual feelings. This was especially true if puberty had already been reached. Issues pertaining to sexuality would most likely need clarification with these victims. The degree to which future sexual relationships are damaged, or if they are, by a rape experience, is in need of more long-term study. What the long-term results are is not known.

The Victim's View of Herself

Most of the issues resulting from rape have been shown to pertain to how a woman will view herself after the assault and how she will integrate this perception into her self-concept. Aspects of the rape have already been discussed which may influence how a woman perceives her responsibility for "precipitating" the attack. Additionally, the reactions of those important to her social network have been looked at. Mingled with these issues is the woman's concept of herself: her 
sexuality, future relationships with men, phobic reactions, and anxiety and depression (Notman and Nadelson, 1976, p. 412; Hilberman, 1976, p. 48). The literature has reported several different findings from studies and psychiatric case studies. These aspects are closely related to each other, particularly as the basis of each is the ability to care about the self, developing of trust and the establishment of relationships. The following discussion of the literature findings will be considered in two broad headings: sexuality and relationships with men, and the woman's self-concept, including anxiety and depression. The phobic reactions have a1ready been considered.

Sexuality and Relationships with Men. Several of the studies have made references to the woman's subsequent sexual adjustment after having been raped. McCombie (1976) reported 15 percent of her sample anticipated problems wi.th sexual adjustment. Notman and Nadelson (1976) noted that women found difficulty in "trusting relationships, particularly with men" ( $p .409$ ), and tended to avoid or be hesitant around them. Burgess and Holmstrom (1974a) used the phrase "compounded reaction" to describe what happened to some of the population of their study. These women were found to exhibit additional problems to the ones other women experienced. Approximately 20 percent of their sample developed compounded reactions. One of the aspects to this reaction was acting-out behavior in their sexual lives. Precisely what forms the sexual activity took was not defined.

Hilberman (1976) reviewed Katan's study of six adult women who had experienced a rape as children. Hilberman remarked about the low selfesteem which she quoted.Katan as stating was a function of "a severe 
disturbance in the fusion of sexual and aggressive drives" (Hilberman, 1976, p. 54).

Relatively little is known about subsequent sexual adjustment to a rape experience. Further research is needed to understand the ways in which women are affected in this area of their.lives. It seems a strange twist of fate that rape has for so long been considered a "sexua1" crime and women have been accused of "wanting it," but so little is known about how it really affects a woman's sexual functioning and adjustment.

The Woman's Self-Concept. The other broad category for the subsequent issues is the woman's view of herself. The emotional impact of the rape was one of the major issues McCombie (1976) found victims identifying for themselves (p. 153). Most of the literature has mentioned a lowered concept of self resulting from rape. Rape "generates selfcriticism and guilt that devalue her [the victim] as a person" (Notman and Nadelson, 1976, p. 409), and has been shown to stigmatize her in society (Weis and Borges, 1973).

In some instances the lowered self-concept was found to be related to depression and suicidal thoughts (Notman and Nadelson, 1976; Burgess and Holmstrom, 1974a). Weis and Borges noted that the women claimed rape resulted in lowered self-esteem and that in interviews by one of the researchers with suicide attempters, "an interesting relationship between an earlier rape experience and suicide was being found" (1973, p. 98).

Some rape victims feel suicidal . . Feeling suicidal concomitant to feeling isolated due to the social stigmatization of rape, the inability to put into words the terror and guilt, and 
the inability to find people who are genuinely empathetic (Pepitone-Rockwell, 1978, p. 523).

Those individuals Burgess and Holmstrom found to have compounded reactions displayed much of the depressed and suicidal behavior. As well, they found symptoms of psychotic and psychosomatic disorders in this type of reaction (1974a, p. 985).

Katan (1973) found in her study of six women that they had turned their anger and aggression inward toward the self.

They were fragmented, they could never feel that they were whole persons: they regarded their own aggression as dangerous and raw, whether it was turned against the self or against the outside world (Katan, 1973, p. 222).

Katan described the women as having "unbelievabiy low self-esteem" (p. 220), and said that they carried an abnormal amount and quality of guilt and were forced to cope with it (p. 221).

The studies have indicated that the self of the rape victim becomes a battle ground for adjusting in the aftermath of the assault. Many of the women experience depression and lowered self-concepts. Weis and Borges (1973) stated it in this manner, "Forced sexual intercourse, apart from the loss of self-determination in the choice of sexual partners, may furthermore result in a change of identity and loss of 'ideal self'" (p. 100). Redefining and reorganizing the self is concomitant with the integration work that Sutherland and Scherl (1970) found rape victims needed to attend to in order to resolve the experience.

Studies have noted women making statements of "feeling dirty" and being "damaged goods" after a rape assault. Such remarks indicate the injury to both the woman's sexual and self identities. Lest all seem hopeless for the victim of rape, one further study needs to be mentioned. 
Sprung (1977) noted that al1 the victims in her sample became introspective, and "some showed evidence of a positive change in their ability to respond to crisis and therefore a growth in their adaptive capacity" (p. 22). These women had been involved in counseling.through the emergency services offered rape victims at a local hospital, and had experienced support throughout the crisis.

\section{CONCLUSION}

The preceding discussion has reported the major research published to date on the reactions to the rape assault. The major findings have delineated either a two- or three-phase response pattern, much like patterns to other traumatizing events. The literature has also suggested that reactions to the assault vary with age. Most of the research has focused on adult forcible rape victims, with a few studies attending to reactions in children.

The second section of the literature review discussed various aspects of the aftermath of the assault, which studies had shown as concerns in adjusting. The basic issues were the victim's feelings of responsibility, the reactions of significant others, developmental stages, and the victim's self-concept. Each of these issues seem to have varying degrees of correlation with each other. Particular attention was given to the victim's sense of being responsible for "precipitating" the rape, as it was hypothesized that many of the other concerns depended on this issue. "The tendency to blame the victim, thereby assigning responsibility to her, fosters guilt and prevents her from adequately working through the crisis" (Notman and Nadelson, 1976, p. 410). 
The overall conclusions point to a tremendous need for more study. Most of the literature supports the paucity of data, in that much of the discussion on long-term adjustment is speculative.

The literature on rape victims makes reference to ego strengths, defenses, object relations, prior adaptation, developmental stresses, and reactions of important others as critical elements in determining the course of adjustments to rape. As yet, there is no empirical research as to whether conditions and characteristics of the assault and the immediate aftermath have any influence on subsequent adjustment (McCombie, 1976, p. 142).

With the incidence of reported rapes rising, the need for understanding the needs and developing services for the affected population is indicated. 


\section{CHAPTER III}

\section{PROCEDURE}

The literature discussing victim reactions to rape indicated the need for more research and, in particular, determination of long-term effects of the assautt. To meet the needs, a questionnaire was deve1oped with the objective of exploring the long-term consequences of rape.

The original intent was to administer the questionnaire to women fifteen years of age or older who had experienced rape at least one year prior, and analyze the data. Difficulties were encountered in securing access to the population desired.

In the fall of 1977 , several agencies in the Portland metropolitan area, whose function was providing services to rape victims, were contacted by phone. Each was contacted with three objectives in mind:

(1) what were the dimensions of their data-gathering instruments;

(2) did they know of victims interested in helping with a long-term study, or could they suggest how to contact rape victims for follow-up; (3) were they doing long-term follow-up studies, or interested in facilitating such research.

The results of the communications were of interest. Both agencies did some follow-up with victims but usually referred the women to other professionals in the community. With one agency, a personal interview with one of the staff members was arranged. This agency's data 
collecting procedures included interviews and a questionnaire documenting characteristics of the assault.

What was of further interest was a remark made during the personal interview in reference to one of the stated objectives of each contact. The staff member stated that aside from the tremendous confidentiality issues involved with finding. women who would be willing to participate in follow-up research, an ethical question existed. She said she was unwilling to ask a woman to re-discuss an event the woman would rather forget; to do so. would be disregarding the rape victim's needs and right to self-determination. When reconsidering the literature documentation of the rape victim's need to feel in control of her life, especially heightened by the assault, and any contact not allowing for her selfdetermination being coercive to her, the interests of the woman seemed best served by following such advice. The objective of administering the questionnaire was discontinued.

A subsequent approach was discovered, but too late to utilize in this practicum. It is being mentioned here as a reference for others who might wish to pursue similar research goals and also have difficulty contacting the population. To allow the woman self-determination it is suggested that the research be published in the local newspapers, and any other media that might reach the desired population. The women can respond to the inquiry at their discretion, in confidence, and they would choose to participate in the study.

This method is ethically sound, but would result in sample bias. It can be expected that those not wanting to discuss the rape, or those having difficulties with adjustment, would not be as likely to respond 
to the advertised inquiry. The results would have to take such limitations into account.

In determining how to approach the formulation of the questionnaire, it seemed logical to review the literature and make questions around the various issues women stated as being of concern to them. Sample statements were gleaned from the literature to determine if some of these same thoughts or statements were being made one year or more after the assault. The underlying hypothesis was that the rape crisis may take longer than six months or a year to resolve, plus impetus was received by noting that most studies were carried out during the crisis period, and very few after the course of one year.

Once developed, a pre-test was difficult to obtain with women who had experienced rape, or were similar to the desired population. It was discovered, however, while discussing the research goals with others, that individual women would volunteer that they had been raped, and would be willing to take the questionnaire and make comments. Their willingness further substantiates the method of contacting the population in question through advertisement and allowing the women to volunteer.

Changes in format were made by the suggestions of the two women who filled out the questionnaire. Some of the questions were deleted and others were added, and the allotted space between questions was increased to visualiy simplify the format. The continuum of responses from "al1 the time" to "never" was inappropriate for some questions, which could be more simply answered by "yes" or "no." Changes were made to place these questions in their own section. It was noted by the two 
women that they did not know what their sexual desires or relationships with men were like previous to the rape, as they were both cases of child rape. These women also remarked they were now abstaining from sexual intimacies for personal or religious convictions; therefore they could not answer questions that discussed subsequent sexual functioning. The column of "doesn't apply/don't remember" was added because of their suggestions.

It was found that the questionnaire took fifteen to twenty minutes to complete. This was found satisfactory as many of the questionnaires used in the literature were stated as taking one to two hours to complete. The objective in this practicum was to limit the amount of time and to systematize the method, rather than depending on open-ended questions as was the indicated procedure for much of the reported research. A discussion of the questions and what they are intended to measure will be found in Chapter IV. 


\section{CHAPTER IV}

\section{DISCUSSION OF THE QUESTIONNAIRE}

The delineated issues and concerns from the literature review pertaining to rape resolutions have been embodied in the questionnaire. The purpose of the questionnaire is to explore long-range effects of the rape assault on women, and incestuous relationships that culminate in actual rape. Specific objectives are:

(1) to identify sequelae of the rape still causing difficulties;

(2) to identify the degree of difficulty;

(3) through comparison of data, to determine if specific issues take longer to integrate, under what conditions, and if a pattern exists;

(4) to be able to correlate characteristics of the rape assault with outcome issues;

(5) to begin to define what "long-term" might mean;

(6) to provide a more systematic method of gathering data;

(7) to substantiate previous research findings.

The questionnaire is divided into basically two sections. The first part asks questions of a factual nature, while the second section focuses on the victims' subjective reactions. It is organized so that computer programming can easily correlate characteristics of the assault with the woman's subjective reactions. Questions 1-45 are of the factual nature. Questions 10-19 are included to determine how the woman 
is treated by authorities and if she experienced additional trauma by having sought help from them. Questions 20-22 are to gather information about social network support, with questions 50 and 52 from the second section to determine how the woman felt about the support.

To gather information about the assault and its characteristics, for correlating with later issues and adjustment, questions 23 to 38 , plus 44 , were included. These inquiries are of particular importance in relation to the woman's perception of her responsibility, as was indicated from the literature discussion. It is expected that a woman who knew her assailant, had been drinking, experienced less violence and perhaps had reacted with incapacitating fear or little physical resistance, would score higher in the second section, in terms of having more responses marked "all the time" or "most of the time."

Other requests of the informative nature have direct bearing on hypotheses indicated by the literature: question 3 relates to developmental or life stage issues; question 5 is included to. test the idea that length of time between the assault and telling someone expresses guilt and feelings of "being responsible"; responses to inquiry 8 are meant to correlate with control and vulnerability issues. It is expected that questions 44 and 45 correlated with a younger age would indicate more difficulties in subsequent sexual adjustment.

To test how the woman views the rape affecting her self-concept, questions 39 and 40 are included. Placement of these two inquiries was found to be a problem. Rather than try to disguise their content, it was decided to place them near each other and openly indicate the information sought. It is anticipated that the two 1-10 scales will produce 
bias as they are now presented. Questions $46,58,73,77,82,86,87$, and 89 are for verification of the responses on the self-image scale. The second section of the questionnaire allows for the respondent to indicate what issues have been easier and which have been more difficult in resolution of the trauma. The statements are formulated from material in the literature and grouped around specific issues. The areas are as follows with the correlating questions indicated:

$\begin{array}{ll}\begin{array}{l}\text { sexuality/relationships } \\ \text { with men }\end{array} & 49,55,56,59,67,74, \\ \begin{array}{l}\text { vulnerability/feeling in } \\ \text { control }\end{array} & 66,67,78,79,54 \\ \begin{array}{l}\text { depression } \\ \text { self-concept }\end{array} & 46,61,64,70,76,82 \\ \text { anger } & 58,73,77,86,87,89 \\ \text { guilt/feelings of being } \\ \text { responsible } \\ \text { resolution } & 60,83 \\ \text { support } & 53,69,75 \\ \text { nightmares } & 47,61,63,68,71,81 \\ \text { phobias } & 50,52 \\ & 51,62,85 \\ & 57,65,72,84,88\end{array}$

Questions 91-102 on the final page of the questionnaire are for determining the woman's coping style (93) and general functioning in 1 ife (91, 92, 94-102). The question about having received mental health treatment previously in her life, and the question about being treated for physical illnesses are to determine her mental stability and previous coping. It must be noted that having sought help through mental health services does not necessarily indicate instability, but may in fact represent strength in being able to recognize when one needs help. It is 
found that delineating the woman's previous satisfaction in life is one of the more difficult areas to incorporate in the questionnaire, and is one of its weaknesses.

A final note on the format of the instrument: the continuum of responses "all the time" to "never" is intended to reveal intensity of the symptom in question. It is expected that the woman with a greater number of responses leaning toward "all the time" and "most of the time" is functioning more poorly in life than a woman with fewer such responses. Such indications would need to be correlated with other information about the specific respondent, however. It is also hoped that the continuum will reveal if patterns exist for sequelae of rape, and give indications about the conditions relating to the patterns.

It should be noted that certain limitations to the instrument exist:

(1) It is set up to be applicable for incest, rape, attempted rape experiences.

(2) There are age limitations. Ages of individuals answering the questionnaire are to be fifteen years and above. It is not designed for victims under fifteen. It is assumed that another, simpler form could be devised for the younger rape victim.

(3) The respondent is to have experienced rape at least one year prior to filling out the questionnaire. It is not intended to measure adjustment or resolution previous to this time duration. 
(4) No standard exists for statistical comparison to determine which responses are expected to be more frequent if poor adjustment exists. The tool is for exploring and defining such data.

It is hoped that the questionnaire can be helpful to counselors working with rape victims, or who discover that one of their clients has been raped in her past, by delineating which issues are giving the woman more difficulty. Therapy could begin from the pinpointed concerns discovered. 


\section{CHAPTER $V$}

\section{RECOMMENDATIONS}

The goal has been to give impetus to research on "long-term" effects of rape and subsequent adjustment. Inclusive with this concern has been the development of a questionnaire embodying the issues that have been delineated as part of the resolution process. As the literature review has demonstrated, there is a paucity of knowledge about long-Tasting sequalae of rape, which can hinder the services rendered to the woman in need, and which makes the formulation of recommendations difficult. It would be helpful at this point, therefore, to reinterate what is known--key issues of the reorganization/resolution phase--so that anyone counseling rape victims can focus treatment to deal with each area and be careful not to add further trauma to the woman.

Studies on responses to the rape trauma find two basic patterns: the two-phased "rape trauma syndrome," and a three-phased pattern which includes an acute reaction, a pseudo-adjustment aspect, and finally, integration and resolution. The initial impact reaction in both of these patterns finds women either "expressing" their feelings by exhibiting shock, crying. or smiling, or "controlling" their feelings by appearing calm or subdued. The reorganization aspect, which takes place after the initial response, is often composed of phobias, nightmares, sexual concerns, depression, and concern of being safe. 
The sequelae of the assault seem to center into basic issues. These are noted as:

(1) The responsibility the woman feels for what happened. This issue is often evidenced in the woman questioning "how she got into the situation," "what could she have done differentiy." In such questioning, the victim will wonder about if she struggled enough, how do others perceive her culpability, where the rape took place, was alcohol involved, and the degree of relationship she has with the offender. It is important to help the woman look at each of these questions realistically and resolve any blame she may feel.

(2) How others will react to the knowledge of the assault. The woman must decide if she will report to the police, seek medical help, prosecute, and tell family members. She may encounter support or suspicion from each of these groups and must deal with their responses to her. Support of her at this stage is suggested as being crucial.

(3) Where she is in life stages. It has been suggested that each of $1 \mathrm{ife}$ 's stages presents different issues of concern and each woman will resolve the rape accordingly. These are important aspects to consider when working with a rape victim.

(4) The woman's view of herself. This issue incorporates a woman's self-concept, her sexual identity, depression, and future relationships with men. The victim will need to give each of these areas attention and work at resolving any conflicts.

(5) Previous Coping abilities. In working with rape victims it would also seem essential to keep in mind that many women with 
previous or concurrent social, psychological, or physical difficulties may incur a "compounded" reaction. These women seem to have more obstacles to overcome to achieve resolution, and will be in need of added support, and perhaps long-term counseling.

The issues have been presented here to indicate what is known about rape, focus the concerns for applicability to victims, but also to demonstrate the areas of disparity. The recommendations that can be suggested at this point focus on the need for more research. It is suggested that delineation and clarification of long-term effects and how characteristics of the assault may affect long-term reactions and the eventual adjustment process are needed. To achieve these objectives, several research questions need to be answered; specifically:

(1) What constitutes "normal" and "pathological" adjustment? This could be determined by first establishing the pattern long-term adjustment seems to follow, the time duration involved, then examining deviations from the pattern, and if such deviations are indicative of poor functioning. The questionnaire presented in Appendix $A$ is conducive to such data analysis.

(2) What issues delineated in the literature are more crucial to successful adjustment? The rape victim can give self-reports as to what issues have been of greater concern. In addition, determination of intensity of each concern through a standardized test can certify the self-reports. Those issues weighted more heavily could be considered as the more important to successful adjustment.

(3) What variables of each issue are more important to successful adjustment? For example, it has been stated in the literature 
review that the degree of violence in the assault may be correlated with the victim's subsequent feelings of responsibility. Determination of this relationship reaching a significance level can be achieved by statistical analysis. It is expected that the variables of each issue can be subjected to such analysis by the proposed questionnaire.

(4) What correlation exists between each characteristic of the assault and the victim's adjustment? Once a standard pattern for adjustment is established, each characteristic can be tested for significance in relation to adjustment. It is possible those women raped in their homes will experience greater difficulty in resolving needs to feel autonomous and in control of their environment.

(5) Is there a correlation between coping styles and subsequent adjustment?

(6) How do women who receive crisis counseling compare in adjustment with those who receive none?

Recommendations for carrying out such research includes suggestions of who would be best suited to the task. It would seem individuals and agencies that encounter the women when in crisis could easily request of the victims participation in follow-up studies as part of the services. It is suggested that studies one to five years after the incident, or of equal time duration if the woman has just remembered the incident, could be sufficient for determining some long-term effects. If the data indicate effects lasting longer, such research could be initiated at that time. Counselors who are referred the rape victims from the various agencies in the metropolitan area could also be contacted 
and perhaps encouraged to collaborate on their information, or approach their clients in terms of participating in follow-up study. A final suggestion is that individuals interested in doing research of long-term rape effects could advertise their intent in the news media and conceivably obtain the sample population in that manner.

It is hoped that services to meet the needs of rape victims can be more effective in reducing long-term effects with better formulated and specific interventions through the means of more knowledge. Additionally, published results can education the public and reduce the tendency to "blame the victim" which often adds to her trauma. It is hoped these ends have been served by providing impetus for research, data collection, and a means to standardize responses. 
REFERENCES CITED 


\section{REFERENCES CITED}

Amir, Menachem. Patterns in Forcible Rape. Chicago: University of Chicago Press, 1977.

Brownmiller, Susan. Against Our Will: Men, Women, and Rape. New York: Simon and Schuster, 1975.

Burgess, Ann Wolpert, and Holmstrom, Lynda. "The Rape Victim in the Emergency Ward." American Journal of Nursing 73 (October 1973): $1740-45$.

- "Rape Trauma Syndrome." American Journal of Psychiatry 131 (September 1974a):981-86.

- Rape: Victims of Crisis. Bowie, Md.: Robert J. Brady Company, 1974b.

- "Coping Behavior of the Rape Victim." American Journal of Psychiatry 133 (April 1976):413-18.

Csida, June B., and Csida, Joseph. Rape: How to Avoid It and What to Do about It If You Can't. Chatsworth, Ca].: Books for Better Living, 1974.

Geis, Gilbert. "Forcible Rape: An Introduction." In Forcible Rape: The Crime, the Victim, the Offender, pp. 1-44. Edited by Duncan Chappe11, Robley Geis, and Gilbert Geis. New York: Columbia University Press, 1977.

Goldberg, Jacob, and Goldberg, Rosamond. Girls on City Streets: A Study of 1400 Cases of Rape. New York: Stettiner Brothers, Incorporated, 1935.

Griffin, Susan. "Rape: The All-American Crime." In Forcible Rape: The Crime, the Victim, the Offender, pp. 47-66. Edited by Duncan Chappe11, Robley Geis, and Gilbert Geis. New York: CoIumbia University Press, 1977.

Hardgrove, Grace. "An Interagency Service Network to Meet Needs of Rape Victims." Social Casework $57(4,1976): 245-53$.

Hilberman, Elaine, M.D. The Rape Victim. New York: Basic Books, Inc., 1976.

Hursch, Carolyn. The Trouble with Rape. Chicago: Nelson-Ha11, Inc., 1977. 
Katan, Anny, M. D. "Children Who Were Raped." The Psychoanalytic Study of the Child. Vol. 28: 208-224. New Haven: Yale University Press, 1973.

McCombie, Sharon. "Characteristics of Rape Victims Seen in Crisis Intervention." Smith College Studies in Social. Work 46 (March 1976): :135-58.

McDonald, John M. Rape Offenders and Their Victims. Springfield, I11.: Charles C. Thomas, 1971.

Medea, Andra, and Thompson, Kath7een. Against Rape. New York: Farrar, Straus, and Giroux, 1974.

Mills, Patrick, ed. Rape Intervention Resource Manual. Springfield, 111.: Charles C. Thomas, 1977.

Notman, Malkah, and Nadelson, Carol. "The Rape Victim: Psychodynamic Considerations." American Journal of Psychiatry 133 (Apri1 1976): 408-413.

Pepitone-Rockwe11, Frances. "Patterns of Rape and Approaches to Care." The Journal of Family Practice $6(3,1978): 527-29$.

Peters, Joseph J. "Child Rape: Diffusing a Psychological Time Bomb." Hospital Physican 9 (February 1973):46-49.

- "Children Who Are Victims of Sexual Assault and the Psychology of Offenders." American Journal of Psychotherapy 30 (July 1976):398-421.

"The Philadelphia Rape Victim Project." In Forcible Rape: The Crime, the Victim, the Offender, pp. 339-55. Edited by Duncan Chappe11, Robley Geis, and Gilbert Geis. New York: Columbia University Press, 1977.

Rado, Sandor. "Pathodynamics and Treatment of Traumatic War Neuros is (Traumatophobia)." Psychosomatic Medicine 4 (1948):362-68.

Russe11, Harold E., and Beigel, Allan. Understanding. Human Behavior for Effective Police Work. New York: Basic Books, Inc., 1976.

Schultz, Leroy G., ed. Rape Victimology. Springfield, I11.: Charles C. Thomas, 1975.

Sprung, Susan. "Resolution of Rape Crisis: Six to Eighteen Month Follow-up." (MSW Thesis Abstract.) Smith College Studies in Social Work $48(1,1977): 22$.

Stratton, John. "Law Enforcement's Participation in Crisis Counseling for Rape Victims." The Police Chief 43 (March 1976):46-49. 
Sutherland, Sandra, and Scherl, Donald. "Patterns of Response among Victims of Rape." American Journal of Orthopsychiatry 40 (Apri1 1970):503-511.

Webster's New Collegiate Dictionary. Springfield, I11.: G. \& C. Merriam Company, 1977.

Weis, Kurt, and Borges, Sandra S. "Victimology and Rape: The Case of the Legitimate Victim." Issues in Criminology 8 (Fal1 1973): $71-115$.

Weiss, R. J., and Payson, H. E. "Gross Stress Reaction I." In Comprehensive Testbook of Psychiatry, pp. 1027-31. Edited by A. M. Freedman and H. L. Kaplan. Baltimore, Md.: Williams and Wilkins, 1967. 
APPENDIX 


\section{APPENDIX}

We are seeking to know how you are now feeling about your rape experience. Your responses could help in understanding how rape affects its victims. The following are statements which have been made by women following their experience. Your answers will be strictly confidential. We want to thank you for your cooperation and your interest in helping other women who may experience rape.

The following information would be beneficial in understanding the circumstances in which you were attacked.

Please fill in the following blanks:

1. Your age when you were attacked

2. Your age now

3. Were you at the time of the rape. single married divorced/separated widowed living with a man

4. What is your status now?

5. How much time passed between the attack and telling someone about it?

6. How much time passed between the attack and reporting it to the police?

7. In the hours immediately following the attack, what did you do?

8. Where did the rape take place?

9. What time of day/night was it? $\mathrm{am}$ pm don't remember 
Please circle the responses which most nearly applied to you:

10. Did you report the incident to the police?

$$
\text { yes }
$$

no

Please circle the responses which most nearly applied to you, and fill in the blanks where indicated:

11. Were they helpful?

$$
\begin{aligned}
& \text { yes } \\
& \text { no }
\end{aligned}
$$

12. Explain how they were or were not helpful

13. Did you go to the hospital or receive medical attention because of the incident?

$$
\begin{aligned}
& \text { yes } \\
& \text { no }
\end{aligned}
$$

14. Were they helpful?

$$
\begin{aligned}
& \text { yes } \\
& \text { no }
\end{aligned}
$$

15. In what ways were they helpful or not helpful?

16. Have you received professional counseling in reference to your experience?

$$
\text { yes }
$$$$
\text { no }
$$

17. Was it helpful?

$$
\text { yes }
$$$$
\text { no }
$$

18. In what ways was it helpful or not helpful? 
Please circle the responses which most nearly applied to you, and fill in the blanks where indicated:

19. Did you go to court regarding the rape?

yes

no

20. Did you tell your closest friend(s) at the time of the attack?

yes

no

some of them

21. Do you tell your closest friend(s) now about what happened?

yes

no

some of them

I'd like to, but I don't

22. Did you tell your:

parents

mother

father

sister

brother

lover

husband

children

boyfriend

other

no one 
Please circle the responses which most nearly applied to you, and fill in the bTanks where indicated:

23. Was the rapist:
a stranger
a friend
a neighbor
a relative
an acquaintance
someone seen in passing
an ex-boyfriend or ex-spouse
other

24. How old was the offender:

$$
\begin{aligned}
& \text { teens } \\
& 20 \text { 's } \\
& 30 \text { 's } \\
& 40 \text { 's } \\
& 50 \text { 's or older } \\
& \text { don't know }
\end{aligned}
$$

25. Were you alone?

$$
\begin{aligned}
& \text { yes } \\
& \text { no }
\end{aligned}
$$

26. Was he alone?

$$
\begin{aligned}
& \text { yes } \\
& \text { no }
\end{aligned}
$$

27. If not, how many offenders were involved?

28. Did the offender(s) have a weapon?

$$
\begin{aligned}
& \text { yes } \\
& \text { no }
\end{aligned}
$$

29. Did the offender(s) threaten he had a weapon?

$$
\text { yes }
$$


Please circle the responses which most nearly applied to you, and fill in the blanks where indicated:

30. Did the offender(s) talk with you as he assaulted you?

yes

no

31. If yes, what kinds of things did he say?

32. Were you:

intimidated
strangled
tied up
beaten
bruised
cut
bleeding
kidnapped
urinated on
threatened with a weapon
threatened verbally
other (specify)

33. Was he under the influence of alcohol or drugs?

yes

no

34. Were you under the influence of alcohol or drugs?

yes

no

35. Did he force you to perform other sexual acts other than intercourse?

yes

no 
Please circle the responses which most nearly applied to you, and fill in the blanks where indicated:

36. What did he force you to do? touch his penis masturbate him put his penis in your mouth anal intercourse al.low him to have oral contact with your vaginal area other (specify)

37. Did he ejaculate?

yes

no

38. How did you react to the attack?

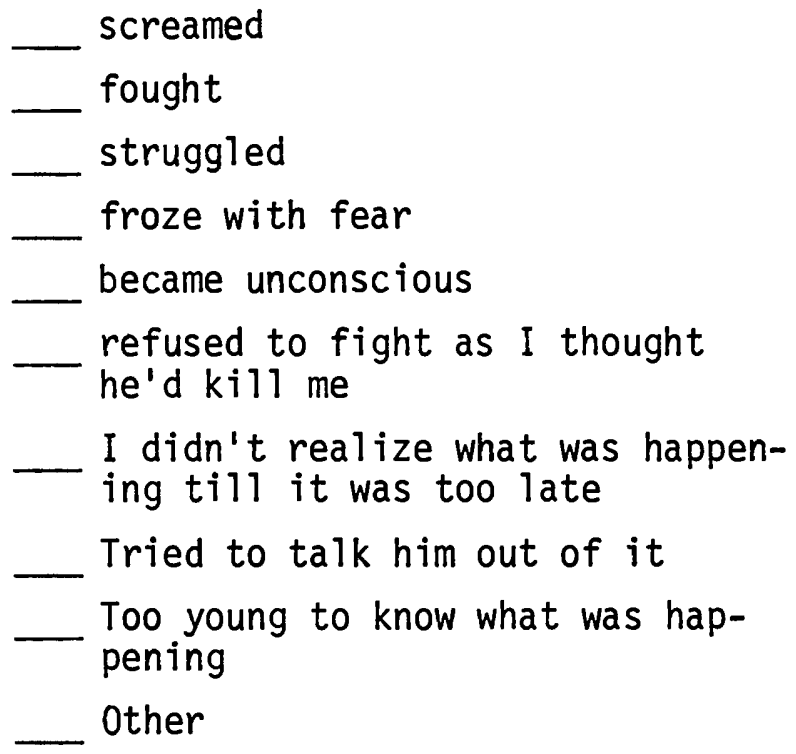

39. How would you rate your self-image on a scale of 1-10 before the attack?

$$
\begin{aligned}
& 1--2--3--4--5--6--7--8--9--10 \\
& \text { low high }
\end{aligned}
$$

40. How would you rate your self-image on the same scale, since the attack?

$$
\begin{aligned}
& 1--2--3--4--5--6--7--8--9--10 \\
& \text { low } \quad \text { high }
\end{aligned}
$$


41. Was there a time lapse between the attack and when you remembered it had occurred?

$$
\begin{aligned}
& \text { yes } \\
& \text { no }
\end{aligned}
$$

42. If yes, how long was the time lapse between the assault and when you remembered it having happened?

43. If yes, what do you think brought it to your attention again?

44. Was the rape your first sexual contact involving intercourse or attempted intercourse?

$$
\begin{aligned}
& \text { yes } \\
& \text { no }
\end{aligned}
$$

45. Do pelvic examinations bother you?

$$
\begin{aligned}
& \text { yes } \\
& \text { no } \\
& \text { don't know }
\end{aligned}
$$

Answer the following statements by circling the letter that is true for you.

Yes No Doesn't apply

46. I feel like my life is all messed up since the rape.

a $\quad$ b $\quad c$

47. I've pretty much forgotten the experience.

a

b

C

48. I feel I'm lucky to have escaped al ive.

a

b

C

49. The rape affected my sex life.

a

b

C

50. My family has helped me through this.

a

b

C 
Answer the following statements by circling the letter that is true for you.

51. I keep having the same dream over again; where I can't get out of a situation.

a

b

C

52. I feel I can't tell my close friends as they won't understand.

53. I've changed the kind of clothes I wear since the rape.

54. I'm more jumpy or startled when people surprise me, than I was before the rape.

a

b

c

55. My relationships with men are more difficult than before the rape.

a

b

C

56. I feel like my interest in sex is about the same as before the rape. a

b

c

Answer the following by choosing how often the statement is true for you and circle the corresponding letter.

\begin{tabular}{|cccccc|}
\hline $\begin{array}{c}\text { Al1 the } \\
\text { Time }\end{array}$ & $\begin{array}{r}\text { Most of } \\
\text { the Time }\end{array}$ & $\begin{array}{c}\text { Some of } \\
\text { the Time }\end{array}$ & $\begin{array}{c}\text { Occa- } \\
\text { sionally }\end{array}$ & Never & $\begin{array}{c}\text { Doesn't } \\
\text { Apply/ } \\
\text { Don't } \\
\text { Remember }\end{array}$ \\
\hline a & b & c & $d$ & e & $f$
\end{tabular}

57. I'm afraid to be by myself at night.

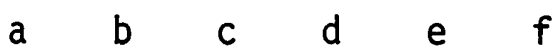

58. I find myself thinking "no man will want me now."

a $\quad$ b $\quad c \quad d$ e $\quad f$

59. I feel more nervous around men than I did before the rape.

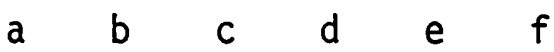


Answer the following by choosing how often the statement is true for you and circle the corresponding letter.

\begin{tabular}{|cccccc|}
\hline $\begin{array}{c}\text { All the } \\
\text { Time }\end{array}$ & $\begin{array}{c}\text { Most of } \\
\text { the Time }\end{array}$ & $\begin{array}{c}\text { Some of } \\
\text { the Time }\end{array}$ & $\begin{array}{c}\text { Occa- } \\
\text { sionally }\end{array}$ & $\begin{array}{c}\text { Doesn't } \\
\text { Apply/ } \\
\text { Don't } \\
\text { Remember }\end{array}$ \\
\hline a & b & c & d & e & $f$
\end{tabular}

60. I think about the man who did this to me.

a $\quad b \quad c \quad d \quad$ e $f$

61. I think, "Oh, what's the use.

I'll never stop thinking about it."

a $\quad b \quad c \quad d \quad$ e $f$

62. I have nightmares about the attack.

a $\quad$ b $\quad c \quad d \quad$ e $\quad f$

63. I get agitated when I hear people talk about rape.

a $\quad b \quad c \quad d \quad$ e $f$

64. I feel all alone in this.

a b c d e f

65. I notice that my body tenses up when I'm in a crowd.

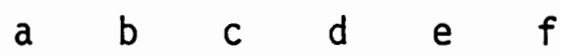

66. I feel like I'm going crazy.

a $\quad b \quad c \quad d \quad$ e $f$

67. I wonder if the new men I meet will assauit me.

$\begin{array}{llllll}a & b & c & d & e & f\end{array}$

68. I find it hard to talk about what happened.

$\begin{array}{llllll}a & b & c & d & e & f\end{array}$

69. I feel like I was "asking for it."

$\begin{array}{llllll}a & b & c & d & e & f\end{array}$

70. I find myself wanting to talk about what happened.

a $\quad b \quad c \quad d \quad$ e $f$

71. I think about the rape.

a $\quad b \quad c \quad d \quad e \quad f$

72. When I hear footsteps behind me I get anxious.

$\begin{array}{lllllllllllllll} & b & b & c & d & e & f\end{array}$

73. I feel "dirty."

a $\quad b \quad c \quad d \quad l e f$

74. I wonder if ['ll ever trust men again.

a $\quad b \quad c \quad d \quad l l l$ 
Answer the following by choosing how often the statement is true for you and circle the corresponding letter.

\begin{tabular}{|cccccc|}
\hline $\begin{array}{c}\text { Al1 the } \\
\text { Time }\end{array}$ & $\begin{array}{c}\text { Most of } \\
\text { the Time }\end{array}$ & $\begin{array}{c}\text { Some of } \\
\text { the Time }\end{array}$ & $\begin{array}{c}\text { Occa- } \\
\text { sionally }\end{array}$ & Never & $\begin{array}{r}\text { Doesn't } \\
\text { Apply/ } \\
\text { Don't } \\
\text { Remember }\end{array}$ \\
\hline a & b & c & $d$ & e & $f$
\end{tabular}

75. I have a nagging thought that others think I did something to cause the rape.

$a \quad b \quad c \quad d \quad l e f$

76. I cry when I think about what happened.

a b c d e f

77. I keep telling myself I'm okay, but I don't feel like I am.

$\begin{array}{llllllllllllll} & b & c & d & e & f\end{array}$

78. I find myself wary of what might happen to me next.

a $\quad$ b $\quad c \quad d \quad$ e $f$

79. I'm afraid I'll get raped again.

a $\quad$ b $\quad c \quad d \quad$ e $\quad f$

80. I find that I'm able to enjoy sex better than I was before the rape.

a $\quad$ b $\quad c \quad d \quad$ e $f$

81. I find my relationships with others are better now, because I feel I can handle things in my life better.

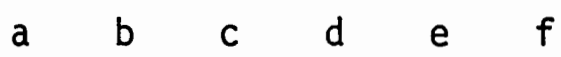

82. I think about "ending it al1."

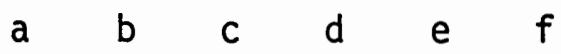

83. I get angry when I think about the guy who did this.

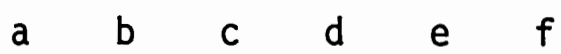

84. I still think I hear the rapist.

a b c d e f

85. When I have nightmares about the rape, I wake up screaming.

a b $\quad$ c $\quad d \quad$ e $f$

86. I wonder how much this has affected me emotionally.

a b c d e f 
Answer the following by choosing how often the statement is true for you and circle the corresponding letter.

\begin{tabular}{|cccccc|}
\hline $\begin{array}{c}\text { Alt the } \\
\text { Time }\end{array}$ & $\begin{array}{c}\text { Most of } \\
\text { the Time }\end{array}$ & $\begin{array}{c}\text { Some of } \\
\text { the Time }\end{array}$ & $\begin{array}{c}\text { Dcca- } \\
\text { sionality }\end{array}$ & Never & $\begin{array}{c}\text { Doesn't } \\
\text { Apply/ } \\
\text { Don't } \\
\text { Remember }\end{array}$ \\
\hline$a$ & b & c & $d$ & e & $f$
\end{tabular}

87. I wonder how I'm adjusting to the rape.

88. When I'm in places similar to where the assault occurred, I feel like running.

a $\quad$ b $\quad c \quad d \quad$ e $f$

a $\quad$ b $\quad c \quad d \quad$ e $f$

89. I wonder if the rape has affected my self-image.

$\begin{array}{lllllll}a & b & c & d & e & f\end{array}$

90. I find I avoid men since the rape.

a $\quad b \quad c \quad d$ e $f$

91. I push myself to get going in the morning.

$\begin{array}{llllll}a & b & c & d & e & f\end{array}$

92. I find getting things done comes easy for me.

$\begin{array}{llllll}a & b & c & d & e & f\end{array}$

93. My friends teil me that when upsetting things happen to me I take it calmly.

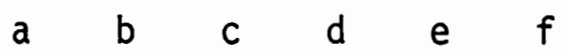

94. I feel satisfied with the relationships I've had in life.

95. When something bothers me I try not to think about it.

$\begin{array}{llllll}a & b & c & d & e & f\end{array}$

96. I find I can't do anthing right.

$a \quad b \quad c \quad d \quad l e f$

97. When I have trouble in a relationship I can usually find a way to resolve the problem

I feel satisfied with.

$a$ b $\quad c \quad d \quad$ e $f$ 
Answer the following by choosing how often the statement is true for you and circle the corresponding letter.

YES

NO

98. Have you ever received professional counseling before, besides about the assault?

a

b

99. Have you ever been hospitalized for an emotional problem?

a

b

100. Within the last year have you experienced any "losses" (death, separation, moving) in relationships?

a b

101. Ever been under a doctor's care for an extended physical illness?

a

b

102. If yes, explain briefly the nature of the illness and its duration

Thank you for your responses and your help. 